\title{
FIRST EXPERIENCES IN THE CLINICAL USE OF EXTRACORPOREAL CIRCULATION
}

\author{
BY \\ A. G. BROM AND J. NAUTA \\ From the Department of Thoracic Surgery, Leyden University Hospital, Netherlands
}

(RECEIVED FOR PUBLICATION OCTOBER 6, 1958)

The literature of the past five years has shown that extracorporeal circulation is increasingly used as an aid in cardiovascular operations, particularly in America, where clinics there already have available data on hundreds of patients (Kirklin, Lillehei, Cooley, Crafoord-Senning). A symposium (Allen, 1958) was recently published, in which an abundance of data had been collected regarding animal experiments, surgical indications, surgical technique, and the biochemical changes involved.

In Europe, however, the number of centres at which extracorporeal circulation is used is at present still limited, but in the future this technique will be more commonly used, and the number of indications for its use is likely to increase. Therefore, although the experience gained elsewhere is considerably wider than ours, we consider it useful to report on the difficulties which we encountered in the first 29 operations performed with the aid of the heart-lung apparatus. We believe that we have made a number of errors, and describing these may be of use to others who wish to start using extracorporeal circulation in the treatment of their patients.

Moreover, the Crafoord-Senning apparatus which we used has not yet been frequently used outside Crafoord's own clinic (Crafoord, Norberg, and Senning, 1957).

\section{EXPERIMENTS}

Anyone who believes that extracorporeal circulation can be used clinically merely by buying a heart-lung apparatus is bound to be rudely disappointed. The surgeon must familiarize himself with the working of the machine, and it is here that the first difficulties arise. The apparatus must be tested and used in experiments on animals, and an attempt must be made to determine the effect of perfusion on the blood cells, the electrolyte composition, the acid-base balance, the blood pressure, the heart action, and the electroencephalogram.
Working this way the peculiarities of the apparatus become familiar, and the results obtained improve so that the team members become more proficient as a team. It is of importance that these experiments should be made in rapid succession lest the experience gained be lost again.

In the first series, all surgical risks such as potassium arrest or ventriculotomy are best avoided. Efforts should be exclusively confined to total or partial bypass until a survival rate of 80 to $90 \%$ has been attained in dogs. Causes of death should be studied. Such a first series can then be followed by a second in which open-heart surgery can be attempted.

\section{Clinical Aspects}

At the completion of our first small series of 29 patients we formed the opinion that the success or failure of the intervention was chiefly dependent on the following factors : (1) Choice of apparatus, (2) choice of patient, (3) blood bank, (4) heparinization, (5) technique of perfusion, (6) surgical technique, (7) controls, and (8) postoperative care.

CHOICE OF APparatus.-The apparatus for extracorporeal circulation which we used is that which has been developed by Crafoord, Senning, and Åstradsson. It was satisfactory at all operations performed, and never gave rise to unexpected difficulties. This was attributable to the quality of the apparatus and to the experience and dedicated skill of the anaesthetist who operated it. It was chosen because it has the following properties :

Gravity Flow.-The venous blood from the venae cavae flows towards the oxygenator at a lower level due to the force of gravity. In this manner a flow is attained that is determined by, and is therefore adjusted to, the individual. This flow varies from 60 to $150 \mathrm{ml} . / \mathrm{kg}$. $/ \mathrm{min}$. The blood flow thus obtained is oxygenated from 65 to 
$70 \%$ venous saturation to about $95 \%$ arterial saturation, and this flow has proved to be sufficient to avoid metabolic acidosis during the perfusion. Yet it should not be believed that this so-called high flow is truly physiological: the cardiac output calculated was often twice the actual flow obtained during perfusion in our patients.

Oxygenation.-This is attained with the aid of six or 12 rotating cylinders, dependent on the size of the flow. Surface oxygenation does not endanger the patient by the passage of small or large air bubbles towards the body. The oxygenator need not first be moistened to obtain a satisfactory blood film. It is unnecessary to treat it with silicone, as no metal or glass comes in contact with blood anywhere.

The Pump Mechanism.-This has very little traumatic effect on the blood. A vertical pump position facilitates air elimination. The output is automatically adjusted: the pump output is small whenever the supply from the venae cavae is small, and large when the supply is large. As a result, the apparatus invariably contains about the same volume of blood. This self-regulating mechanism is mechanical rather than electrical. The pump is automatically stopped when the supply of blood from the venae cavae becomes very low, entailing a risk of air embolism. We believe that such a device fitted to the apparatus is of advantage, particularly at high flows with a varied supply from the cardiotomy sucker.

Filling the apparatus with the connected tubes required 1,500 to $3,000 \mathrm{ml}$. blood, dependent on the size of the oxygenator:

\begin{tabular}{ll|l|l|l}
\hline Flow (l./min.) $\ldots$ & Up to $1 \cdot 8$ & $1 \cdot 8-3 \cdot 5$ & $>3 \cdot 5$ \\
No. of cylinders in oxygenator.. & 6 singles & 12 singles & 12 doubles \\
Priming volume of system & $\ldots$ & $1,500-$ & $2,500-$ & $2,500-$ \\
& & $2,000 \mathrm{ml}$ & $3,000 \mathrm{ml}$. & $3,000 \mathrm{ml}$. \\
\hline
\end{tabular}

Choice of Patients.-The primary success of the operation, i.e., the patient's survival in hospital, is largely dependent on the choice of patients. It has become clear to us that, as the American literature also points out, only those patients have a good chance of surviving the operation who are given "curative" treatment. At the same time, however, diagnostic accuracy should be raised to such a level that the operating surgeon cannot be confronted with surprises; an exploratory operation with the aid of extracorporeal circulation is something to be avoided at any cost.

The inexperienced in this field should be careful to refrain from operating on patients where the favourable stage for operation is already past, e.g., in the case of ventricular septal defect when increase in pressure in the pulmonary artery is marked, or in the case of mitral insufficiency $\frac{\bar{N}}{\bar{N}}$ with marked pulmonary changes and a significant increase in the size of the heart.

It is our opinion that no conditions should be treated using extracorporeal circulation if satis- $\vec{\circ}$ factory results can be obtained by a simpler method. An example is found in the case of $\vec{\omega}$ atrial septal defect of the second type. Operation in these cases requires no extracorporeal circula- $\vec{x}$ tion as hypothermia is an equally effective and $\vec{\omega}$ simpler expedient.*

In our opinion, the ideal patient for extra- $y$ corporeal circulation is a child aged 6-10 years $\checkmark$ who has a ventricular septal defect. The indication $\frac{9}{2}$ is determined by severe complaints of fatigue and $\vec{\nabla}$ recurrent respiratory infections. These patients are often retarded in growth. The prognosis $\overparen{\Phi}$ is better when pulmonary resistance is only moderately increased.

BLOOD BANK.-The heart-lung apparatus is $\vec{\varphi}$ filled with heparinized blood, with which blood $\%$ lost during perfusion is also replenished $(450 \mathrm{ml}$. blood, $20 \mathrm{mg}$. heparin, $10 \mathrm{ml}$. human albumin $20 \%, 40 \mathrm{ml}$. $0.9 \% \mathrm{NaCl}$ ).

Before the perfusion and afterwards citrated blood rather than heparinized blood is given $\frac{2}{\Phi}$ $(410 \mathrm{ml}$. blood, $90 \mathrm{ml} .3 .3 \%$ disodium citrate, and $\stackrel{2}{\overrightarrow{7}}$ $3.3 \%$ glucose).

The question as to how much work this $\frac{3}{5}$ involves for the blood bank staff, and how many donors are required, cannot be categorically answered. The answer is dependent on the procedure used at the blood bank. There are $\underset{x}{\vec{D}}$ various possible methods (Tauxe and Magath, $\stackrel{x}{\sigma}$ 1958), but arrangements at our blood bank are as 3 . follows :

For an operation during which a flow of more $\frac{3}{3}$ than 2 litres $/ \mathrm{min}$. is expected, 3 litres must be응 available for filling the oxygenator. In such a case 4 litres of heparinized blood are reserved o for perfusion, and $2 \frac{1}{2}$ litres of citrated blood for use before and after perfusion. At the blood or bank, blood from each donor is cross-matched N with blood from the patient and from every other N donor. Since these tests are carried out in dup- 0 licate, and by two different methods (in saline and by the indirect Coombs test), this totals a few hundred tests to be carried out for a single perfusion. Obtaining the blood and the addi- 0 tional tasks adds up to two days' work for two laboratory technicians.

If we are to perform one operation per week, $\frac{?}{\mathbb{Q}}$ 15 donors are summoned for this operation (eight $\frac{\mathrm{O}}{0}$

*In our clinic 95 cases were treated in this manner (five deaths). 
for heparinized blood, five for citrated blood, and two reserves); consequently, at this rate, 750 donors per annum are required. If donors are willing to furnish blood twice yearly, then the number of donors must be increased by 350 to 450 donors at a rate of one operation per week. At a rate of two operations per week the increase will be $700-900$.

It is obvious that special difficulties arise in the treatment of patients of rare blood groups.

All this emphasizes the great importance of consulting the blood bank physician a few months before the first perfusion, so that he may prepare himself for the problems with which he will be confronted.

Heparinization.-A low blood heparin concentration entails a risk of damage to the thrombocytes. We therefore administer $3 \mathrm{mg}$. heparin per $\mathrm{kg}$. body weight. This dosage also has the advantage of ensuring that the heparin level in the patient before perfusion is as high as that in the apparatus (in which the donor blood contains $4 \mathrm{mg}$. $/ 100 \mathrm{ml}$.). In this respect the blood volume is presumed to be $7 \frac{1}{2} \%$ of the body weight. The mixture of the patient's blood with blood from the apparatus during perfusion then exerts no influence on the heparin level in the patient. Since $1 \mathrm{mg}$. heparin is neutralized by $1 \mathrm{mg}$. protamine, it is sufficient after the perfusion to give the patient the same quantity of protamine as he received of heparin before the perfusion.

In our laboratory, moreover, a heparin titration of the patient's blood is carried out immediately before the bypass, while the blood from the machine is titrated during perfusion. In this way it is possible to calculate the quantity of heparin in the patient during and therefore also after the perfusion. This value is used as a control and, if necessary, as a maximum limit in protamine administration.

In one case, the control value obtained by titration revealed an error: this value was considerably lower than we expected. A check-up showed that the infusion system used in injecting the heparin was not correctly connected to the needle in the patient's arm: the quantity of heparin administered, therefore, was less than it was supposed to be.

Technique of Perfusion.-In our clinic the apparatus is operated by an anaesthetist, assisted by a technician. During perfusion, their main task is to continue to check the flowmeter connected with the tube between the venae cavae and the oxygenator. To them the flowmeter indicates the perfusion value. Even the slightest decrease in flow can be read immediately; it must be interpreted and then corrected. Such a decrease is often caused by one of the surgeons compressing a venous tube. On the other hand, it may be due to loss of blood in the thorax, in which case blood must be supplied to the system.

During perfusion we use two suction pumps; one is an ordinary surgical pump with a high vacuum, as a result of which a relatively large degree of haemolysis takes place and the blood thus drained is not suitable for further use. The second suction pump, the so-called cardiotomy pump, is connected to the first part of the oxygenator by means of a tube running through a finger pump. The suction here is less strong, and less haemolysis occurs. We use this pump when blood must be drained from the heart for some considerable time, e.g., in cases of tetralogy of Fallot, in which much blood enters the lung via collaterals and bronchial arteries and emerges into the left atrium.

The cardiotomy pump is also used at the end of a perfusion at which potassium arrest has been used ; afterwards when the clamp is removed from the aorta the coronary vessels are filled and as a result the heart fills. Since no contractions occur initially, this results in a dilatation, which in its turn impedes contraction. Dilatation can be avoided by leaving a suction tube in the incision in the right heart instead of closing it completely. We are now accustomed to place this tube in the pulmonary artery because blood also flows back from the lungs into the pulmonary artery, so that the lungs and left heart would become congested when the pulmonary valves were closed. Suction on this tube need only be slight but should not be applied until the heart has been completely closed, lest air should be sucked into the heart.

Placing a tube in the left atrium, as recommended by Kolff, Effler, Groves, Hughes, and McCormack (1958), can certainly be advantageous. We have repeatedly used this method and with success in cases of ventricular septal defect if a large quantity of bronchial blood emerges from the pulmonary veins into the left atrium, and also in cases of Fallot's tetralogy. The field of operation is kept dry in this manner. It is important to realize that by applying suction to this tube air is introduced into the left heart and may be driven to the brain by cardiac contraction after potassium arrest has been concluded.

Although the temperature can be allowed to decrease somewhat during perfusion (a decrease 


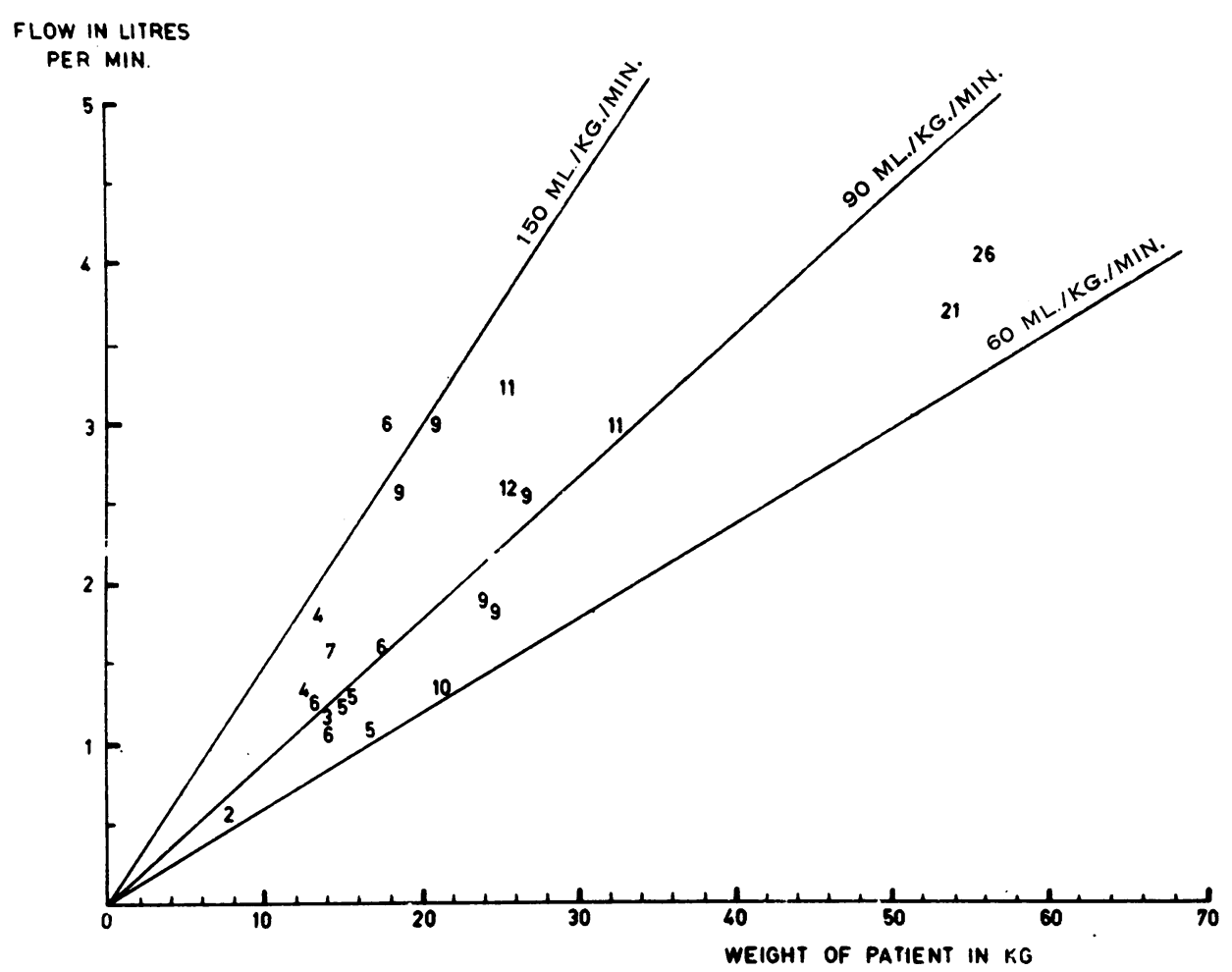

FIg. 1.-Relation between the average flow (by gravity) and the weight of the patient. The numbers in the diagram indicate the ages of the patients. Note that in children flows may vary between 60 and $150 \mathrm{ml} . / \mathrm{kg}$. $/ \mathrm{min}$. for the same age.

regarded as an advantage by some), we made it a rule to warm up the oxygenator by means of the device fitted for this purpose, but in spite of this precaution the temperature fell to an average of $34.3^{\circ} \mathrm{C}$. In five patients treated without warming the oxygenator, the average temperature at the end of perfusion was $30.1^{\circ} \mathrm{C}$. No complications were seen.

Our cardiologists have not hitherto succeeded in calculating in advance the flow to be expected during a perfusion. They do make an advance report on each patient, furnishing data such as the cardiac output calculated and the flow to be expected with the apparatus connected. The flow is calculated on the basis of the following data : (1) $90 \mathrm{ml} . / \mathrm{kg} . / \mathrm{min}$. in children and $70 \mathrm{ml} . / \mathrm{kg} . /$ min. in adults ; (2) 2.31 l./sq.m. body surface/ min. ; (3) $4 \mathrm{ml}$. $\mathrm{O}_{2}$ supply $/ \mathrm{kg}$. $/ \mathrm{min}$.

The actual flow was often found to be lower than that calculated in this manner, particularly in children under 6 years of age. In a few cases the actual flow was higher, and the venous saturation was also high. The first calculation, $90 \mathrm{ml} . / \mathrm{kg} . / \mathrm{min}$. , proved to be nearest the truth, although there were still a great many deviations (Fig. 1).

In all cases the flow was sufficiently high to avoid metabolic acidosis. In only four patients out of 18 was a shift in this sense seen, in the 3 acid-base balance the $p \mathrm{H}$ decreasing no lower than 7.32.

During the total bypass the lung is kept partly expanded with the aid of $100 \%$ helium. Anaesthesia otherwise does not differ from that currently used in our clinic.

Surgical Techique.-It is not our intention N to dwell on the surgical, technical details which $N$ are of great importance in the correction of vari- N ous intracardiac defects. Papers published on $\underset{-}{0}$ this subject are generally known.

We do wish to predict that any surgeon without $\frac{}{\Phi}$ considerable experience in intracardiac surgery $\stackrel{\mathcal{P}}{\rightarrow}$ will find it difficult rapidly to recognize the 0 anatomical changes within the open heart. In $\bar{O}$ addition, the surgeon must at that time realize the $\stackrel{\mathbb{Q}}{\stackrel{Q}{Q}}$ condition as relative to other vital parts of the $\mathbb{\mathbb { D }}$ heart, such as the bundle of His or the aortic valves. Since a curative approach is essential, all 
these structures must be recognized. The surgeon is guided by the following:

(a) A thorough study made in advance in the anatomical laboratory ;

(b) As complete a cardiological examination as possible ;

(c) The possession of a heart-lung apparatus that does not force him to hurry during the operation ;

(d) Palpation of the heart via the right auricle, and determination of the localization of the thrills ;

(e) Arrest of the heart's action by means of anoxia, potassium citrate, or acetylcholine.

Only very seldom need a patient be lost on the table. The greatest difficulties are to be expected within the first 24 post-operative hours, and the cause of death will not always be understood. It is of importance, for these reasons also, that anything that may give rise to post-operative complications be avoided, so that incisions in the skin, muscles, and thoracic wall should be as small as possible. In the case of an ostium primum defect, a right-sided anterolateral thoracotomy is sufficient. Ventricular septal defects can be closed using a transverse skin incision followed by medial sternotomy. This incision is particularly favourable in cases of Fallot's tetralogy, where collaterals can be saved in this way, thus reducing the risk of after-haemorrhage ; this holds true in particular in cases with a previously made palliative anastomosis.

It seems to us to be logical that the incision in the ventricle must also be small. We have seen that under cardiac arrest a very small incision is sufficient.

Haemostasis should be painstakingly accurate. There are no findings indicative of a haemorrhagic diathesis due to extracorporeal circulation, but it is certainly a boon to the surgeon to be able to exclude a haemorrhage as a possible cause of a post-operative decrease in blood pressure. The internal mammary artery cannot be inspected carefully enough before the thorax is closed. In imitation of Senning (personal communication), we did not close the thorax in a few cases until the clotting time had returned to normal, and haemorrhage was no longer seen.

Like most other surgeons we generally use the femoral artery for insertion of the arterial cannula; only in small infants is the left subclavian artery selected for this purpose.

Arresting the heart's action is, in our opinion, a great advantage to the surgeon. The usual solu- tion of $2 \frac{1}{2} \%$ potassium citrate in blood is fairly rapidly injected into the aorta until the heart stops. The needle used is fitted with a small adjustable ring, by means of which perforation of the aorta on the posterior side is prevented. A tobacco-pouch suture is made in advance at the site of injection in the aortic adventitia. If this suture were made in the wall proper, then troublesome after-haemorrhages might occur after the clamp had been removed from the aorta.

Potassium arrest was used in 19 cases. The average duration of perfusion was 23 minutes (10-40 minutes). In only two cases was ventricular fibrillation seen afterwards; the normal rhythm was restored without difficulty. The duration of perfusion in these two cases was 26 and 35 minutes respectively.

Anoxic arrest was used in eight cases. Fibrillation occurred in three, which also was amenable to control. Perfusions in these cases lasted 12, 14, and 35 minutes.

It seems to us to be of importance to effect cardiac standstill during the open-heart procedure. The quiet field not flooded by blood facilitates surgery. The type of arrest that deserves preference is dubious. Figures suggest that fibrillation is more likely to occur in the case of anoxic arrest. Even if this is true, this does not necessarily mean that this is more harmful to the patient than potassium arrest without fibrillation.

In this connexion an operation for rupture of an aneurysm of the aortic sinus in an adult may be mentioned. At operation it was unfortunately found that considerably more extensive changes existed, viz., a large ventricular defect in the usual site, two defects between the aorta and the pulmonary artery, and perforations in the adjacent aortic valve and pulmonary valve. Detection and correction of these defects required two and a half hours. The aorta was clamped off throughout this period, and anoxic arrest was maintained. No potassium citrate was used. After the clamp had been removed from the aorta the heart soon resumed beating, without fibrillation. The blood pressure attained was unfortunately insufficient, and the patient died soon afterwards. Retrograde perfusion of the coronary vessels was recognized in retrospect as the appropriate procedure.

A prosthesis of compressed "ivalon" was used to close a ventricular septal defect in six cases. We now close most defects by direct suturing and reserve "ivalon" for the large ones.

In a case of a mild type of Fallot's tetralogy it was necessary to place a prosthesis in the outflow 


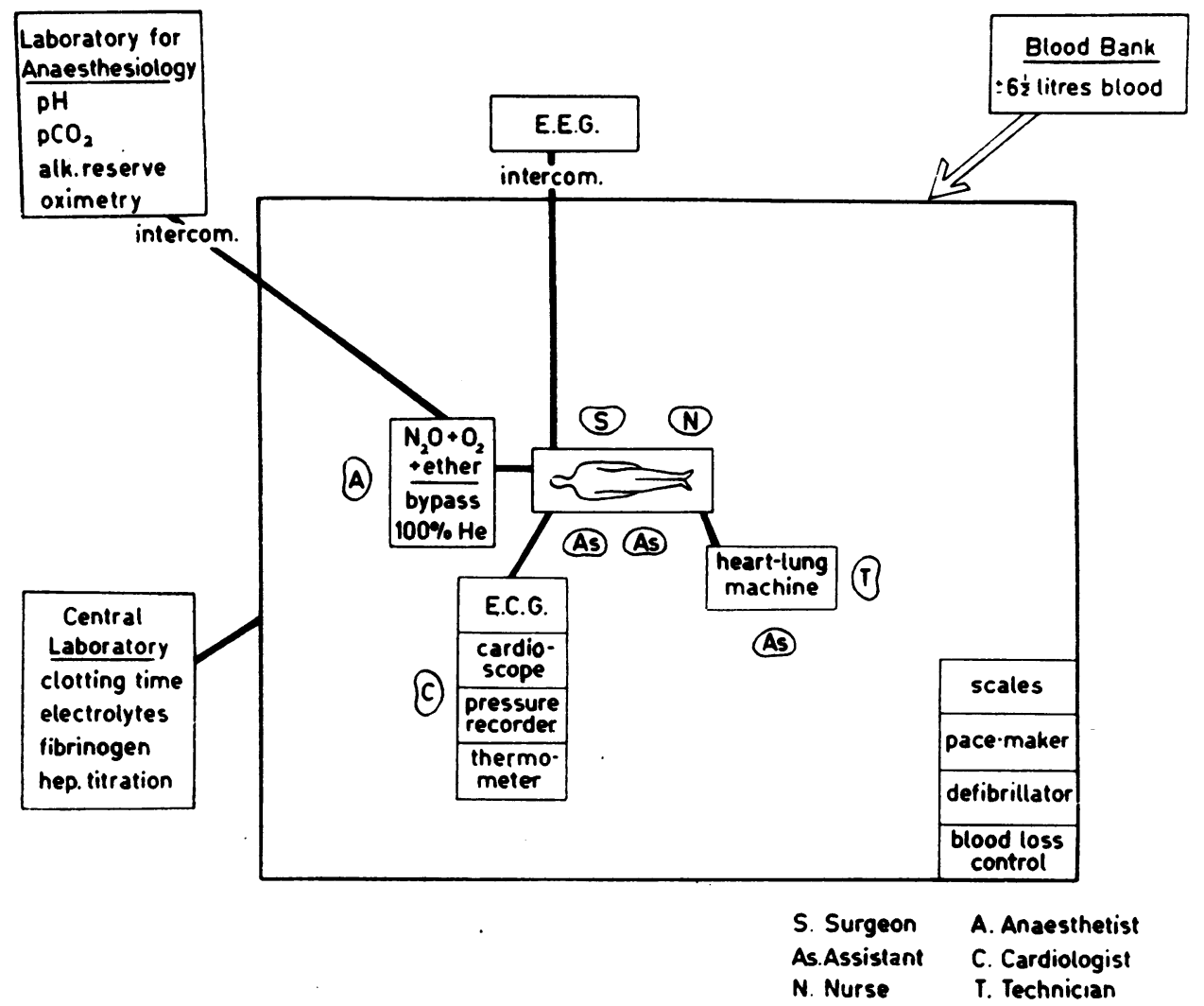

FIG. 2.-Arrangement of the operating theatre during an operation with extracorporeal circulation.

tract of the pulmonary artery. The operation was successful.

An ostium primum in the atrial septum defect was invariably closed by means of a prosthesis. Direct closure in these cases gives rise to undue deformity and insufficiency of the atrioventricular valves.

ConTrols.-In this first series of patients a relative abundance of physical and chemical data has been obtained. This is bound to be reduced to the extent to which our experience increases.

Before the Operation.-Electroencephalography, the electrolyte plan, liver function tests, the protein pattern, and a thrombocyte count are performed. Immediately before the operation the body weight is determined, using a weighing machine with a horizontal platform that can also be used after the operation.

During Operation.-The patient is submitted to continuous electroencephalographic recording on five channels, with a frequency analyser; the E.E.G. operator is in communication with the surgeon through a microphone (Fig. 2).
The arterial pressure (and the venous pressure if necessary) can be read continuously from a cardioscope. The pressures are intravascularly determined in the radial artery and the vena basilica.

The E.C.G. is of importance, particularly after the perfusion, in order to obtain information on disturbances of rhythm after cardiac suturing.

The temperature is electrically determined in the oesophagus ; this is of importance, for example, in biochemical determinations.

A large scoring-board on the wall of the $N$ operating theatre shows the quantity of blood or $\underset{\omega}{N}$ other fluid lost or infused. Any member of the team can thus read the balance at any given time.

During the operation, and for a few hours afterwards, the acid-base balance is checked by a : member of the department of anaesthesia $(p \mathrm{H}$, $\mathrm{pCO}_{2}$, and alkali reserve).

During Perfusion.-The quantity of circulating blood is read from the flowmeter. Blood pres- $\unrhd$ sure in the tube between the arterial pump and $\overline{2}$ the arterial cannula is also supervised in case of 
any obstruction to inflow in the patient. Samples are taken from the machine finally to determine haemolysis and oxygen saturation at the beginning of perfusion and at its completion.

It is important to obtain information as to whether the surgical intervention has had the haemodynamic effect desired. This can be checked after perfusion by determining pressure and oxygen saturation at various different places. In one case, after closure of a ventricular septal defect and cleavage of a valvular pulmonary stenosis, it was found that another important stenosis was formed by the annulus of the pulmonary ostium, with a systolic gradient of 110 $\mathrm{mm}$. $\mathrm{Hg}$; extracorporeal circulation was reinstituted, and the outflow tract was enlarged with the aid of an "ivalon" prosthesis. After this the gradient completely disappeared.

After the Operation.-Immediately after the operation the patient is weighed; a thoracic radiograph is taken and the clotting time, haemoglobin value, and thrombocyte count are determined. The blood pressure is then brachially measured by auscultation or oscillometry. The arterial and the venous cannulae are not removed from the arm until the following morning, as intravascular determination of pressures may be desirable if there are complications.

To cause least possible inconvenience to the patient, the rectal temperature is electrically determined during the first post-operative night.

Value of These Controls.-The various determinations as described have frequently been of paramount importance to us. Yet it may be pointed out again that a correct diagnosis, a correct determination of the indications for surgery, and a flawless surgical technique are the factors which determine the result of the operation.

During perfusion the most important data on the patient's condition and on the circulation are not found in the various biochemical determinations but are the cardiographic blood pressure, flowmeter readings, and the E.E.G. findings. With these data, the quality of the perfusion can be kept entirely under control.

The scoring-board on the wall, giving constant readings on blood uptake and output, has only a relative value. Determination of the postoperative weight showed that errors amounting to $200-300 \mathrm{ml}$. are possible. Yet, for the time being, we would hesitate to do without this record, particularly during prolonged perfusions involving a major loss of blood.

Haemolysis is dependent on the flow and the duration of perfusion; also on the number of cylinders in the oxygenator and on the quantity of blood returned via the cardiotomy pump. This is expressed in outline in the following values:

\begin{tabular}{|c|c|c|}
\hline & $\begin{array}{c}\text { One } \\
\text { Oxygenator } \\
\text { (6 Cylinders) }\end{array}$ & $\begin{array}{c}\text { Two } \\
\text { Oxygenators } \\
\text { (12 Cylinders) }\end{array}$ \\
\hline 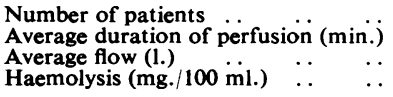 & $\begin{array}{l}7 \\
29(11-40) \\
1 \cdot 2(0 \cdot 6-1 \cdot 6) \\
34(14-67)\end{array}$ & $\begin{array}{l}11 \\
24(13-37) \\
2 \cdot 1(1-3 \cdot 1) \\
46(2-56)\end{array}$ \\
\hline
\end{tabular}

The oxygen saturation of the arterial and venous blood during the bypass was invariably satisfactory, as shown in the following scheme:

\begin{tabular}{|c|c|c|c|}
\hline & $\begin{array}{c}\text { One } \\
\text { Oxygenator } \\
\text { (6 Cylinders) }\end{array}$ & $\begin{array}{c}\text { Two } \\
\text { Oxygenators } \\
\text { (12 } \\
\text { Cylinders) }\end{array}$ & $\begin{array}{c}\text { Three } \\
\text { Oxygenators } \\
\text { (12 Double } \\
\text { Cylinders) }\end{array}$ \\
\hline $\begin{array}{l}\begin{array}{l}\text { Number of patients } \\
\text { Average flow (l.) }\end{array} \\
\text { Arterial saturation }(\%) \\
\text { Venous saturation }(\%)\end{array}$ & $\begin{array}{l}9 \\
1 \cdot 24(550- \\
1,800) \\
94(92-96) \\
66(50-80)\end{array}$ & $\begin{array}{l}13 \\
2 \cdot 2(1,100- \\
3,200) \\
94(91-96) \\
69(51-82)\end{array}$ & $\begin{array}{l}2 \\
4(3,800- \\
4,200) \\
95(95-96) \\
75(71-79)\end{array}$ \\
\hline
\end{tabular}

The influence of the procedure of extracorporeal circulation on the blood coagulation mechanism is still a subject open to considerable discussion, and the data collected here by Dekker and Loeliger (personal communication) warrant as yet no definite conclusions. It : is an established fact, however, that the thrombocyte count shows a slight, insignificant decrease, and the decrease in fibrinogen level as found in most of our patients was not such as to entail a risk of haemorrhagic diathesis. Failure of the clotting time to return to normal after the operation is only too readily ascribed by the surgeon to a disturbance in coagulation, particularly if a decreased fibrinogen concentration is demonstrated in the laboratory. In several cases, however, we have observed a return to normal clotting times even before the precious fibrinogen had reached us from the dispensary.

It is useful to keep a check on the acid-base balance during and after the bypass. More important, however, is the continuous supervision of clinical manifestations and circumstances. The biochemical determinations are merely sample tests to confirm what was expected. Yet they have often proved very useful, particularly during the post-operative period.

Acid-base balance determinations $\left(p \mathrm{H}, \mathrm{pCO}_{2}\right.$, and alkali reserve) were made in all cases in the laboratory (averaging 12 determinations of this balance per case). Fewer determinations will doubtless be sufficient in the future. Determinations were continued throughout the afternoon after the operation. 
The changes in the blood $p \mathrm{H}$ during and after the operation are for the most part connected with the respiration. Since perfusion is as a rule preceded by hyperventilation, this period is characterized by respiratory alkalosis, with a decrease in alkaline reserve. Stanbury and Thomson (1952) believe that this involves an escape of organic acids from the cells into the extracellular space to replace the $\mathrm{CO}_{2}$ in the $\mathrm{BHCO}_{3}$. The serum potassium decrease seen during the operation in a few cases is also believed to be a result of changes in the cellular metabolism during hyperventilation. A decrease in potassium was also seen during hyperventilation as used in hypothermia in our clinic (Boeré, Derlagen, and Kiers, 1957).

A decrease in $p \mathrm{H}$ during perfusion due to metabolic influences was rare. In the four cases in which this phenomenon occurred, the $p \mathrm{H}$ did not fall below 7.32.

After perfusion, too, $p \mathrm{H}$ shifts are as a rule of respiratory origin. Metabolic acidosis can occur in the event of prolonged hypotension.

Post-operative Care.-Within the first 24 post-operative hours it is as a rule necessary to have one of the surgeons in attendance at the patient's bedside. It is obvious that this places a heavy strain on the team. Exact observation during this period, however, may be of vital importance to the patient, and at the same time the surgeon has an opportunity to study the postoperative course, during which there are still so many phenomena which have so far remained unexplained.

In the patient's room apparatus for intubation, ventilation, and control of cardiac standstill should be available and ready for instant use. Oxygen is supplied via a nasal tube. The blood pressure is determined at frequent intervals. A survey of the blood and fluid balance is kept up to date. An electrical thermometer furnishes the rectal temperature readings. Ice packs are applied when readings exceed $39^{\circ} \mathrm{C}$.

Post-operative complications are manifested by respiratory or circulatory disturbances.

If respiration is insufficient, as shown by too high a $\mathrm{pCO}_{2}$ level or too low an arterial saturation, then the cause is frequently to be found in accumulation of secretions in the bronchi. In such cases there was often a previous history of recurrent bronchitis and overfilling of pulmonary vessels. Insufficient respiration can also be seen in patients whose general condition is unfavourable due to myocardial or cerebral injury. All these cases require a tracheotomy without hesita- tion. We perform tracheotomy in the case of insufficient respiration during the post-operative period no longer attributable to the anaesthesia. If the $p \mathrm{H}$ still fails to return to normal then respiration can be controlled with the aid of a positive-negative respirator.

Circulatory difficulties become apparent on the E.C.G. and in the blood pressure readings. All patients are digitalized before and after the operation.

In the case of decreasing blood pressure the first possibility to be considered is an intrathoracic haemorrhage, which need not be manifest on the thoracic radiograph. An intrathoracic haemorrhage is dangerous, particularly following bilateral thoracotomy. In such cases a positive pressure is soon built up in both hemithoraces, and a very dangerous condition gradually develops: the initially restless patient becomes quiet and, although the blood pressure is not yet stabilized, the surgeon may believe that improvement is occurring. At this moment, however, a secondary thoracotomy is indicated in order to remove the clots from the thorax, thus improving the respiration. It is sometimes difficult to determine the appropriate moment, but being too early is always preferable to being too late.

If it is believed that blood has not accumulated in the thorax, and if the E.C.G. offers no explanation of the decrease in pressure, then blood can be infused as long as the venous pressure remains normal. In several cases we ha' $\mathrm{e}$ thus introduced into the circulation a quantity of blood so that the blood volume exceeded that beiore the operation (as concluded from weight $\mathrm{r} \epsilon$ adings). We are unable to offer an explanation of this phenomenon.

If the pressure remains low although no blood is accumulated in the thorax and blood is sufficiently replenished, then a cardiac cause must be sought for. This may be supported in some cases by E.C.G. changes. The cause of the decreased myocardial function is still obscure. Possibilities include an injury caused by the potassium citrate or by anoxia during the perfusion, or by the myocardial incision. Another possible explanation lies in changes in the metabolism of the muscle.

No effective measures against this so-called cardiac hypotension are known to us. In such cases we administered noradrenaline, although we are aware that this is an additional strain on the heart. These cases as a rule had a fatal issue. In two cases we saw a combination of prolonged hypotension, corrected with noradrenaline and 
metabolic acidosis. The use of "isuprel" seems to be more logical.

If the blood pressure remains satisfactory during the first 24 post-operative hours, then the further post-operative course is almcst certain to be uneventful. Pulmonary infections are treated in the usual way. Pre-operative and postoperative physiotherapy is indispensable. Patients get out of bed on the first post-operative day.

\section{RESULTS}

The number of patients so far treated in our clinic with the aid of extracorporeal circulation is too small, and the period of follow-up too short, to warrant any definite conclusions.

In the accompanying Table the causes of death have been divided into three sections, viz., surgical error, erroneous indication, and "unknown." In cases in which cardiac insufficiency seemed to be the cause of death, the designation " unknown" was used, which expresses how little we understand as yet of this cardiac cause of death. Zimmerman, Martins de Oliveira, Nogueira, Mendelsohn, and Kay (1958) used the expression "poor haemodynamic adaptation" for this situation, without, however, giving a solution for the problem.

Under the heading ventricular septal defect all patients are found who were suffering from this

\begin{tabular}{|c|c|c|c|c|c|}
\hline Condition & 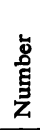 & 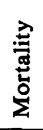 & 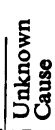 & 宽 & 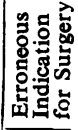 \\
\hline 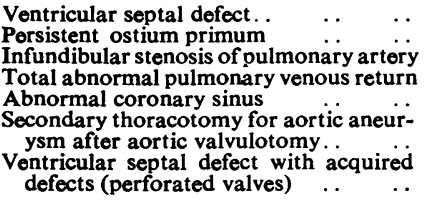 & $\begin{array}{r}18 \\
5 \\
2 \\
1 \\
1 \\
1 \\
1\end{array}$ & $\begin{array}{l}5 \\
2 \\
0 \\
0 \\
1 \\
1 \\
1\end{array}$ & $\begin{array}{l}1 \\
1\end{array}$ & 3 & $\begin{array}{l}1 \\
1\end{array}$ \\
\hline & 29 & 10 & 3 & 4 & 3 \\
\hline
\end{tabular}

anomaly, independent of the degree of pulmonary hypertension. Two of these cases showed the tetralogy of Fallot.

\section{SUMMARY}

Using the extracorporeal circulation in the laboratory and in the clinic we have committed some mistakes.

After these errors and with the aid of the experience of others we developed a routine that was useful. This procedure is presented. It is bound to become simpler as our experience increases.

Operations with the aid of a heart-lung machine are only possible in a good team. We therefore wish to acknowledge the help we received from many colleagues, especially J. W. J. Brands, who was responsible for the perfusions with the machine. Our thanks are also due to J. J. van Rood, from the blood bank ; the cardiologists C. Bruins and H. A. Snellen ; W. A. L. Dekker and E. A. Loeliger performed the chemical and biochemical determinations. The anaesthetic was given by Miss $\mathbf{N}$. Derlagen and L. A. Boeré. The acid-base balance was determined in the laboratory by Miss D. T. Kiers. Much valuable information was obtained with the electroencephalographic recordings made by W. Storm van Leeuwen. A great debt of gratitude is owed to successive resident medical officers for their help and devotion to the experimental work which preceded clinical use of the extracorporeal circulation.

\section{REFERENCES}

Allen, J. G., ed. (1958). Extracorporeal Circulation. Charles C. Thomas, Springfield, Ill.

Boeré, L. A., Derlagen, N., and Kiers, D. (1957). Arch. chir. neerl. 9,155

Crafoord, C., Norberg, B., and Senning, A. (1957). Acta chir. scand., 112, 220.

Kolff, W. J., Effler, D. B., Groves, L. K., Hughes, C. R., and McCormack, L. J. (1958). Cleveland Clin. Quart., 25, 65.

Stanbury, S. W., and Thomson, A. E. (1952). Clin. Sci.,11, 357.

Tauxe, W. N., and Magath, T. B. (1958). J. Amer. med. Ass., 166, 2136.

Zimmerman, H. A., Martins de Oliveira, J., Nogueira, C., Mendelsohn, D., and Kay, E. B. (1958). J. thorac. Surg., 36, 12. 